\title{
Erratum to: Interesting Interest Points
}

\section{A Comparative Study of Interest Point Performance on a Unique Data Set}

\section{Henrik Aanæs • Anders Lindbjerg Dahl • Kim Steenstrup Pedersen}

Published online: 16 April 2014

(C) Springer Science+Business Media New York 2014

\section{Erratum to: Int J Comput Vis (2012) 97:18-35 DOI 10.1007/s11263-011-0473-8}

The authors provided the wrong reference for the FAST corner detector in the paper titled "Interesting Interest Points" by Henrik Aanæs, Anders Lindbjerg Dahl and Kim Steenstrup Pedersen, published March 2012, Volume 97, Issue 1, pp 18-35.

The authors cited Trajkovic' \& Hedley (1998): Fast corner detection. Image and Vision Computing, 16(2), 75-87.
The online version of the original article can be found under doi:10.1007/s11263-011-0473-8.

H. Aanæs · A. L. Dahl $(\varangle)$

DTU Informatics, Technical University of Denmark, Lyngby, Denmark

e-mail: abd@imm.dtu.dk

H. Aanæs

e-mail: haa@imm.dtu.dk

K. Steenstrup Pedersen

E-Science Center, Image Group, Department of Computer Science,

University of Copenhagen, Copenhagen, Denmark

e-mail: kimstp@diku.dk
The reference should have been to the method named FAST where the correct references are: Rosten \& Drummond (2005): Fusing points and lines for high performance tracking. IEEE International Conference on Computer Vision, and Rosten \& Drummond (2006): Machine learning for highspeed corner detection. European Conference on Computer Vision. The error occurs on pages 20 and 21. 